\title{
Сравнительный анализ мер социальной поддержки населения в странах ЕАЭС в период глобальной пандемии
}

\author{
Нурсымбат Сабыр ${ }^{1}$, Назерке Әбілқайыр²

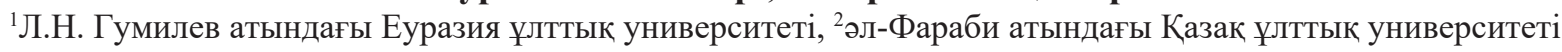

\begin{abstract}
Аннотация
В настоящей статье проведен сравнительный анализ социальной политики государств - членов ЕАЭС, в период пандемии корона вируса 2020 года. Рассмотрены ключевые направления социальной политики, проведен обзор эффективности социальных мер защиты населения. В рамках борьбы с пандемией коронавируса правительства государств - членов ЕАЭС предприняли комплекс мер по выходу из кризиса и социальной поддержке населения. Авторами статьи проведен сравнительный анализ эффективности проводимой социальной политики, направленной на поддержку населения в период пандемии. Сравнительный анализ социальной политики проводимой странами - членами ЕАЭС в период пандемии показал наличие единого комплекса мер социальной поддержки. Это, прежде всего, выплаты по безработице и нетрудоспособности, выплаты семьям, имеющим детей, субсидирование жилищно-коммунальных платежей, и льготное кредитование. Страновая специфика характеризуется объемами сумм предоставленных пособий и критериями отбора объектов предоставления пособий. Необходимость предоставления мер поддержки населения на протяжении продолжительного времени, обусловленное общей ситуацией с коронавирусом в мире, оказывает существенное давление на государственные бюджеты стран и может привести к возрастанию государственного долга и усугублению общеэкономических проблем.
\end{abstract}

Ключевые слова: социальная защита, социальная поддержка, пандемия, ЕАЭС, социальная политика

\section{Ғаламдық пандемия кезеңінде ЕАЭО жағдайында халықты әлеуметтік қолдаудың салыстырмалы тәжірибесі Түйін}

Бұл мақалада ЕАЭО-қа мүше елдерінің 2020 жылғы корона вирусының пандемиясы кезіндегі әлеуметтік саясатына салыстырмалы талдау жасалған. Әлеуметтік саясаттың негізгі бағыттары қарастырылып, халықты қорғау жөніндегі әлеуметтік шаралардың тиімділігіне шолу жасалған. Коронавирустық пандемиямен күрес шеңберінде ЕАЭО-қа мүше елдердің үкіметтері дағдарыстан шығу және халыққа әлеуметтік қолдау көрсету бойынша шаралар кешенін қабылдады. Мақала авторлары пандемия кезінде халықты қолдауға бағытталған әлеуметтік саясаттың тиімділігіне салыстырмалы талдау жүргізді. Пандемия кезеңінде ЕАЭО - ға мүше елдері жүргізіп отырған әлеуметтік саясатты салыстырмалы талдау әлеуметтік қолдау шараларының бірыңғай кешенінің бар екенін көрсетті. Бұл, ең алдымен, жұмыссыздық пен еңбекке жарамсыздық бойынша төлемдер, балалы отбасыларға төлемдер, тұрғын үй-коммуналдық төлемдерді субсидиялау және жеңілдетілген несие беру. Елдің ерекшелігі ұсынылған жәрдемақы сомаларының көлемімен және жәрдемақы беру объектілерін іріктеу критерийлерімен сипатталады. Әлемдегі коронавирусқа байланысты ұзақ уақыт бойы халықты қолдау шараларын ұсыну қажеттілігі елдердің мемлекеттік бюджеттеріне айтарлықтай қысым жасайды және мемлекеттік қарыздың өсуіне және жалпы экономикалық проблемалардың шиеленісуіне әкелуі мүмкін.

Түйін сөздер: әлеуметтік қорғау, әлеуметтік қолдау, пандемия, ЕАЭО, әлеуметтік саясат

\section{Comparative experience of social support for the population in the context of the EAEU during the global pandemic}

Annotation

This article provides a comparative analysis of the social policies of the EAEU member states during the 2020 corona virus pandemic. The key directions of social policy are considered, a review of the effectiveness of social measures to protect the population is carried out. As part of the fight against the coronavirus pandemic, the governments of the EAEU member states have taken a set of measures to overcome the crisis and provide social support to the population. The authors of the article carried out a comparative analysis of the effectiveness of the social policy aimed at supporting the population during a pandemic. A comparative analysis of the social policy pursued by the EAEU member countries during the pandemic showed the presence of a single set of social support measures. These are, first of all, payments for unemployment and disability, payments to families with children, subsidies for housing and communal payments, and preferential loans. The country specificity is characterized by the amount of benefits provided and the criteria for selecting the objects of granting benefits. The need to provide support measures for the population for a long time, due to the general situation with coronavirus in the world, puts significant pressure on the state budgets of countries and can lead to an increase in public debt and aggravation of general economic problems.

Keywords: social protection, social support, pandemic, EAEU, social policy 


\section{Введение}

Глобальная пандемия внесла свои коррективы в современное экономическое пространство, освятив социальные проблемы мирового сообщества, и выдвинув на первый план человека и его здоровье как высшие ценности государства и общества. Евразийский экономический союз (далее по тексту - ЕАЭС), как глобальное интеграционное объединение территориально и экономически близких друг другу держав, вынуждено было действовать в соответствии с реалиями, объявив глобальный локдаун, и осуществив перевод населения и бизнеса на карантинные меры. Жизнь на карантине обнажила проблемы социальной дифференциации, поставив остро вопрос об обеспечении малоимущих слоев населения минимальным пороговым уровнем дохода.

В рамках настоящей статьи проводится сравнительный анализ мер социальной защиты и поддержки населения в странах ЕАЭС в период пандемии.

Целью настоящей статьи является рассмотрение комплекса мер, направленных на поддержку населения в период пандемии и анализ их эффективности.

В работе использованы методы эмпирического, сравнительного анализа, статистической оценки, индукции и дедукции.

\section{Методология}

В рамках борьбы с пандемией коронавируса правительства государств - членов ЕАЭС предприняли комплекс мер по выходу из кризиса и социальной поддержке населения. Исходя из цели нашего исследования, для проведения сравнительного анализа определены ключевые показатели, характеризующие качество и количество реализуемых антикризисных мер.
Обеспечение социальной защиты населения характеризуется показателями наличия социальных выплат, которые могут быть классифицированы по нескольким группам:

- социальные выплаты трудоспособному населению, временно потерявшими работу в период локдауна - определяются через количество выплат, произведенных трудоспособному населению в сопоставлении с величиной прожиточного минимума;

- выплаты социально уязвимым группам населения, таким как многодетные семьи, инвалиды, пенсионеры, и др., определяются через дифференциацию выплат социально уязвимым группам на удовлетворение базовых потребностей (выплаты на покупку продуктов питания, частичная или полная оплата коммунальных услуг, выплаты беременным женщинам, выплаты на малолетних детей);

- оценка эффективности социальных выплат посредством проведения сравнительного анализа номинального и реального прожиточного минимума - показывает, какой объем базовых потребностей в действительности способны покрыть произведенные социальные выплаты.

\section{Результаты и обсуждения}

По состоянию на начало 2021 года в состав ЕАЭС входят 5 суверенных государств - Республика Казахстан, Российская Федерация, Республика Беларусь, Республика Кыргызстан, Республика Армения. Эпидемия корона вируса обусловила максимальную мобилизацию средств государственного бюджета и экономических субъектов на снижение негативных последствий от введения карантинных мер на экономику во всех странах участницах ЕАЭС. Подходы и объемы выделяемой помощи по странам существенно отличаются (таблица 1).

Таблица 1 - Сравнительный анализ структуры мер социальной поддержки в странах ЕАЭС в период пандемии коронавируса

\begin{tabular}{|l|c|c|c|c|c|}
\hline \multicolumn{1}{|c|}{ Страна } & $\begin{array}{c}\text { Наличие } \\
\text { соц. выплат }\end{array}$ & $\begin{array}{c}\text { Предоставление } \\
\text { единоразовых выплат } \\
\text { населению, временно } \\
\text { потерявшему работу }\end{array}$ & $\begin{array}{c}\text { Поддержка } \\
\text { многодетных } \\
\text { семей и семей } \\
\text { с детьми }\end{array}$ & $\begin{array}{c}\text { Поддержка } \\
\text { пожилых } \\
\text { людей }\end{array}$ & $\begin{array}{c}\text { Оплата } \\
\text { коммнальных } \\
\text { услуг }\end{array}$ \\
\hline Республика Казахстан & + & + & + & + & + \\
\hline Российская Федерация & + & + & + & + & + \\
\hline Республика Армения & + & + & - & - & - \\
\hline Республика Беларусь & - & - & - & - & + \\
\hline $\begin{array}{l}\text { Р е с п у б л и к а - } \\
\text { Кыргызстан }\end{array}$ \\
\hline \multicolumn{2}{|l}{ Примечание - Источники $[1,2,4,9]}$. \\
\hline
\end{tabular}


Страновой анализ показал, Правительство Республики Беларусь и Республика Кыргызстан не вводило жестких ограничений для экономики страны, и соответственно, не производили дополнительные социальные выплаты населению, связанные с карантином.

В Республике Беларусь не было предпринято практически никаких мер борьбы с коронавирусной инфекцией и мер оказания социальной поддержки населению. Правительство ограничилась мерами стимулирования экономики, которые включали пересмотр ставки рефинансирования Национального банка страны. В соответствие с Постановлением Правления Национального банка от 18 мая 2020 г., № 155 «Об изменении постановления Правления Национального банка Республики Беларусь от 18 января 2013 г. № 34», ставка рефинансирования была снижена до 7,75 процентных пункта, что, соответственно, удешевило кредиты для населения и бизнеса [13].

Республика Кыргызстан также не приняла значительных социальных мер поддержки населения, кроме единичного комплекса обязательных к исполнению предписаний, анонсированных Национальным банком Республики Кыргызстан. В частности, Постановлением Правления Национального банка КР «О некоторых временных решениях Национального банка Кыргызской Республики по вопросу установления экономических нормативов и требований, обязательных для выполнения коммерческими банками и небанковскими финансово-кредитными организациями Кыргызской Республики» № 2020-П-12/15-7-(НПА)» [14], предусматривался ряд мер, направленных на поддержку населения и бизнеса для минимизации последствий коронавирусной инфекции. В соответствии с указанным Постановлением банкам рекомендовалось реструктуризировать долги заемщиков, продлив срок погашения по кредитам минимум на 6 месяцев, запрещалось взимать комиссии при пересмотре кредитных договоров, и разрешалось не понижать класс заемщика на более рискованный при пересмотре кредитного договора на анонсированных Национальным банком условиях.

В Республике Казахстан, Российской Федерации и Республике Армения социальные выплаты производились.

В целом на борьбу с пандемией Президент Республики Казахстан выделил 5,9 трлн. тенге (\$13,98 млрд или 9,0\% ВВП), из которых 2,5 - внебюджетные средства, а 3,4 трлн.
- средства республиканского бюджета, что в расчете на численность населения составляет 314372,25 тенге на одного казахстанца (около \$752). Целевым назначением расходования выделенных средств выступает повышение доступности здравоохранения, денежные выплаты лишившимся заработка и на поддержку бизнеса. В Казахстане к решению вопросов защиты социально уязвимых категорий населения подошли комплексно. Так, согласно, Приказу Председателя Агентс-тва РК по регулированию и развитию финансового рынка от 26 марта 2020 года, № 167 [1] была осуществлена реструктуризация долга с приостановлением выплат по обслуживанию долга для социально уязвимых категорий населения, получателей адресной помощи и безработных, кроме того, был введен запрет на начисление процентов по просроченным кредитам физических лиц.

В России на борьбу с последствиями пандемии было выделено 2,9 трлн. рублей средств, $\quad(\$ 39,77$ млрд., эквивалентно $2,7 \%$ ВВП) что в расчете на душу населения составляет 19830 рублей (\$267). Выплаты включали поддержку многодетных семей, лиц, оставшихся без работы в период пандемии, также за гражданами сохранялись все базовые пособия, получаемые ими до наступления пандемии. Постановлением Правительства РФ от 4 июля 2020 года, № 980 регионам было перечислено порядка 4 млрд. руб. на создание дополнительных рабочих мест, в соответствии c реализуемой мерой поддержки населения в период сокращения общего количества рабочих мест и загруженности производств. $\mathrm{B}$ соответствии $\mathrm{c}$ указанной мерой было трудоустроено свыше 80 тыс. человек [9].

Республика Армения в рамках борьбы с пандемией, приняла ряд значимых законов, направленных на борьбу с пандемией. Реализация социальной помощи уязвимым категориям населения была оказана в ходе двух значительных кампаний. Первая кампания по выплате пособий была осуществлена в весенний период 2020 года. В частности, Решением Коменданта Республики Армения Тиграна Авиняна № 54, от 23.04.2020 г., о внесении изменений и дополнений в решение Коменданта Республики Армения № 27, от 31.03.2020 г., были определены социально - уязвимые категории населения, которые находятся в ключевой зоне риска от COVID-19, именно им была оказана приоритетная помощь [12]. Правительством Республики Армения было принято специальное Постановление № 577-Л, от 17.04.2020 года, о выплате всем уязвимым 
категориям населения специального пособия. Всего для поддержания экономики Армении было принято 13 мер, которые включали предоставление льготных кредитных ресурсов малому и среднему бизнесу, в том числе, были предоставлены кредиты по выплате заработной платы на сумму более 20 млрд. драмов (более \$1 млрд.). Из них 13 млрд. 159 млн. драмов было выделено на поддержку малого бизнеса, в том числе свыше 1 млрд. драмов на поддержку малого семейного бизнеса. Порядка 4 млрд. 343 млн. драмов было выделено на поддержку сельскохозяйственных предприятий, на которых занято порядка $30 \%$ социально уязвимого населения, с доходами ниже прожиточного минимума (было утверждено более 3100 заявок от таких предприятий). Цель поддержки данной категории предприятий преимущественно состояла в предоставлении оборотных средств под выплату заработной платы работникам на контрактной основе, для многих из которых сезонная работа является основным источником дохода на семью.

Одной из ключевых мер поддержки является осуществление единовременных выплат населению, потерявшему работу в связи с пандемией. Сравнительный анализ по странам показал, что сумма производимой выплаты была максимально приближена к объему прожиточного минимума (таблице 2).

Таблица 2 - Сравнительный анализ социальных выплат лицам, потерявшим работу в период пандемии в странах ЕАЭС (по состоянию на 31.05.2020 г.)

\begin{tabular}{|l|c|c|c|c|c|}
\hline Страна & $\begin{array}{c}\text { Количество } \\
\text { человек, } \\
\text { получивших } \\
\text { выплаты } \\
\text { (млн. чел.) }\end{array}$ & $\begin{array}{c}\text { Процент населения, } \\
\text { получившие } \\
\text { выплаты по } \\
\text { безработице (\%) }\end{array}$ & $\begin{array}{c}\text { Выплаты } \\
\text { (в млн. } \\
\text { ед. нац. } \\
\text { валюты) }\end{array}$ & $\begin{array}{c}\text { Сумма выплат } \\
\text { на человека (в } \\
\text { тыс. ед. нац. } \\
\text { валюты) }\end{array}$ & $\begin{array}{c}\text { Прожиточный } \\
\text { минимум (в } \\
\text { тыс. ед. нац. } \\
\text { валюты) }\end{array}$ \\
\hline Республика Казахстан & 2,3 & 12,2 & $\begin{array}{c}97750 \\
\text { KZT }\end{array}$ & 42,50 тыс.KZT & 31,18 тыс.KZT \\
\hline Российская Федерация & 2,2 & 1,5 & $\begin{array}{c}16982 \\
\text { RUB }\end{array}$ & 12,13 тыс.RUB & 12,39 тыс.RUB \\
\hline Республика Армения & 0,7 & 2,7 & $\begin{array}{c}53720 \\
\text { AMD }\end{array}$ & 68,00 тыс.AMD & $\begin{array}{c}63,55 \text { тыс. } \\
\text { AMD }\end{array}$ \\
\hline \multicolumn{7}{|l|}{ Примечание - Источники [9, 10,11]. } \\
\hline
\end{tabular}

Так, в Российской Федерации произошло увеличение выплат по безработице до 12130 руб., что составляет примерно $98 \%$ от среднего значения прожиточного минимума в стране. В России уровень прожиточного минимума рассчитывается каждым регионом самостоятельно. В Российской Федерации социальная поддержка населения в период пандемии осуществлялась посредством увеличения предоставления выплат по больничным листам, предприятия были обязаны представлять выплаты в размере не менее 1 минимального размера оплаты труда (МРОТ). Гражданам, которые потеряли работу и были признаны безработными после 1-го марта 2020 года, предоставляется пособие по безработице в максимальном размере (12 130 рублей с 27-го марта) за апрель, май, июнь, а если в их семье имеются дети в возрасте до 18 лет, то размер пособия повышается на дополнительно 3000 рублей за каждого ребенка. Им воспользовались 2,2 млн. чел.
В Республике Армения выплаты составили 68000 драмов, что составляет порядка 92\% прожиточного минимума и выплатами воспользовались около $2,7 \%$ населения. Особенность получения данного вида помощи была связана с рядом условий: помощь полагалась гражданам Республики Армения, заработная плата которых не превышала 500000 драмов за предшествующие 2 месяца до начала пандемии, и они не работали в финансовом секторе, либо игорном бизнесе.

В Казахстане рамках поручения Президента РК Токаева К.К., от 10.04.2020 г [2] социально уязвимым категориям граждан, и индивидуальным предпринимателям, пострадавшим от пандемии производились индивидуальные выплаты в размере 42500 тенге на человека, что составляет $101 \%$ от официального уровня прожиточного минимума. Выплаты получили порядка 12,2\% трудоспособного населения. В Казахстане на получение пособия подали заявления 4,701 
миллиона человек или $51,1 \%$ от рабочей силы Казахстана, из них было удовлетворено заявок 2,3 млн. граждан Республики Казахстан.
Проведенный анализ показал, что выплаты, предусмотренные в период пандемии превышают прожиточный минимум в среднем по региону минимально на 16,76\% в столице г.Нур-Султан, и максимально на $50,71 \%$ в Западно - Казахстанской области (таблица 3).

Таблица 3 - Сравнительный анализ эффективности выплат в период пика пандемии по сравнению с прожиточным минимумом по состоянию на 01.04.2020 года

\begin{tabular}{|c|c|c|c|c|c|}
\hline & $\begin{array}{l}\text { Количество } \\
\text { человек, } \\
\text { получивших } \\
\text { выплаты } \\
\text { (чел.) }\end{array}$ & $\begin{array}{c}\% \text { от } \\
\text { трудоспо- } \\
\text { собного } \\
\text { населения }\end{array}$ & $\begin{array}{c}\text { Совокупная } \\
\text { сумма } \\
\text { выплат, } \\
\text { тыс. тенге }\end{array}$ & $\begin{array}{c}\text { Величина } \\
\text { прожиточного } \\
\text { минимума, } \\
\text { тыс. тенге }\end{array}$ & $\begin{array}{c}\text { Превышение } \\
\text { государственных } \\
\text { выплат над уровнем } \\
\text { прожиточного } \\
\text { минимума по региону } \\
(\%) \\
\end{array}$ \\
\hline г. Нур-Султан & 1521 & 0,26 & 64642,5 & 36,4 & 16,76 \\
\hline г. Алматы & 3500 & 0,37 & 148750 & 35,2 & 20,74 \\
\hline г. Шымкент & 8037 & 1,86 & 341572,5 & 29,2 & 45,55 \\
\hline Акмолинская обл. & 2299 & 0,55 & 97707,5 & 30,2 & 40,73 \\
\hline Актюбинская обл. & 2102 & 0,48 & 89335 & 28,4 & 49,65 \\
\hline Алматинская обл. & 13548 & 1,33 & 575790 & 31,8 & 33,65 \\
\hline Атырауская обл. & 929 & 0,28 & 39482,5 & 30,3 & 40,26 \\
\hline ВKO & 3435 & 0,49 & 145987,5 & 31,4 & 35,35 \\
\hline Жамбылская обл. & 5436 & 1,03 & 231030 & 29,0 & 46,55 \\
\hline ЗКО & 1230 & 0,36 & 52275 & 28,2 & 50,71 \\
\hline $\begin{array}{l}\text { Карагандинская } \\
\text { обл. }\end{array}$ & 2195 & 0,65 & 93287,5 & 30,0 & 41,67 \\
\hline Костанайская обл. & 1886 & 0,38 & 80155 & 29,4 & 44,56 \\
\hline $\begin{array}{l}\text { Кызылординская } \\
\text { обл. }\end{array}$ & 3075 & 0,89 & 130687,5 & 29,8 & 42,62 \\
\hline Мангистауская обл. & 1328 & 0,41 & 56440 & 36,2 & 17,40 \\
\hline Павлодарская обл. & 1522 & 0,38 & 64685 & 28,4 & 49,65 \\
\hline СКО & 2457 & 0,80 & 104422,5 & 29,1 & 46,05 \\
\hline Туркестанская обл. & 6321 & 0,76 & 268642,5 & 31,2 & 36,22 \\
\hline
\end{tabular}

По данным официальной статистики, средний уровень прожиточного минимума по Казахстану в 2020 году составил 18,5 тыс. тенге, при росте годовой инфляции на 7\%.Для оценки эффекта от предоставления одноразовых выплат, проведем сравнительный анализ номинальной и реальной стоимости потребительской корзины за исследуемый период (таблица 4).

В соответствии с представленными данными видно, что реальные траты одного домохозяйства в месяц составляют порядка 54,5 тыс. тенге, что на 28,89\% выше уровня выплат, предлагаемых государством. Денежных средств, выплачиваемых государством недостаточно для покрытия минимальных ежемесячных потребностей средней казахстанской семьи, так как расчет стоимости потребительской корзины производится на одного человека. В этой связи наиболее уязвимыми остаются многодетные семьи. Анализ мер поддержки многодетных семей представлен в таблице 5 . 
Таблица 4 - Номинальная и реальная стоимость потребительской корзины казахстанцев по состоянию на 01.04.2020 года

\begin{tabular}{|l|c|c|c|}
\hline \multicolumn{1}{|c|}{ Структура корзины } & $\begin{array}{c}\text { Номинальная стоимость } \\
\text { (тыс. тенге) }\end{array}$ & $\begin{array}{c}\text { Реальная стоимость } \\
\text { (тыс. тенге) }\end{array}$ & $\begin{array}{c}\text { номинальной стоимости } \\
\text { к реальной стоимости } \\
(\%)\end{array}$ \\
\hline Траты на продукты питания, & 8,9 & 30,8 & 28,89 \\
из них: & 3,16 & 11,27 & 28,03 \\
\hline мясопродукты & 1,91 & 8,17 & 27,38 \\
\hline молоко, сыр и яйца & 2,61 & 9,53 & 69,94 \\
\hline фрукты и овощи & 1,28 & 1,83 & 40,51 \\
\hline хлеб и крупа & 9,6 & 23,7 & 33,94 \\
\hline Непродовольственные товары & 18,5 & 54,5 & \\
\hline Итого & \multicolumn{2}{|c|}{} \\
\hline \multicolumn{2}{|l|}{ Примечание - Составлено автором на основе данных источника [6]. } \\
\hline
\end{tabular}

Таблица 5 - Анализ выплат многодетным семьям (по состоянию на 31.05 .2020 г.)

\begin{tabular}{|c|c|c|c|c|}
\hline Страна & $\begin{array}{c}\text { Количество } \\
\text { семей, } \\
\text { получивших } \\
\text { выплаты (тыс. } \\
\text { семей.) }\end{array}$ & $\begin{array}{c}\text { Всего произведено в } \\
\text { ыплат многодетным } \\
\text { семьям (в млн. ед. } \\
\text { нац. валюты) }\end{array}$ & $\begin{array}{c}\text { Сумма } \\
\text { выплат на } \\
\text { семью. (в } \\
\text { тыс. ед. нац. } \\
\text { валюты) }\end{array}$ & $\begin{array}{c}\text { Прожиточный } \\
\text { минимум (в тыс. } \\
\text { ед. нац. валюты) }\end{array}$ \\
\hline Республика Казахстан & 22 & $33 \mathrm{KZT}$ & $15,00 \mathrm{KZT}$ & $31,18 \mathrm{KZT}$ \\
\hline Российская Федерация & 25000 & 2702RUB & 10,00RUB & 12,39 RUB \\
\hline Республика Армения & 101 & 46 AMD & $26,50 \mathrm{AMD}$ & 63,55 AMD \\
\hline
\end{tabular}

В соответствии с представленной таблицей 5, видно, что в Республике Казахстан дополнительные выплаты получили порядка 22000 многодетных семей, семьям предоставлялись выплаты в размере 15000 тенге на погашение коммунальных услуг в дополнение к регулярной государственной помощи, которая выплачивалась многодетным семьям до пандемии.

В Российской Федерации выплаты получили свыше 25 млн. семей, сумма выплат составила по 10000 руб. на каждого ребенка до 16 лет включительно. В соответствии с Указом Президента с 1 января 2020 года семьям с низкими доходами ежемесячно выплачивались дополнительные пособия на детей до 7 лет в размере половины прожиточного минимума по региону, порядка $\$ 80$ на ребенка (6000 руб.).

Также была осуществлена адресная поддержка семей в период пандемии оставшихся без доходов, которая осуществлялась на основе расчета дохода семьи за последние 6 месяцев, и составляла не менее 1 размера МРОТ в расчете на человека. Помимо этого, Президент Российской Федерации распоря- дился выплатить семьям с детьми до 7 лет по 5000 рублей к Новогодним праздникам, подписав Указ 17 декабря 2020 года. Всего на поддержку регионов в период пандемии было выделено порядка 78 млрд. рублей (свыше 1 млрд. долларов), средства были перераспределены за счет экономии на бюджетных трансферах, до конца 2021 года регионы освобождены от необходимости выплачивать проценты за пользование бюджетными трансферами [16].

Согласно Постановлению Правительства РФ от 31 декабря 2020 года, № 2391 [17], граждане Российской Федерации могут получить субсидии на оплату коммунальных услуг, в размере до 50\% их стоимости, если стоимость коммунальных услуг составляет свыше 10\% от дохода семьи для Москвы и Московской области, и свыше 14\% для прочих регионов. В Республике Армения, выплаты каждой многодетной семье составили 26500 драм, всего выплатами воспользовались свыше 101000 семей.

Можно отметить, что произведенные социальные выплаты составляют менее 50\% для Республики Казахстан и Республики 
Армения, и порядка 90\% для Российской Федерации от суммы прожиточного минимума по странам.

\section{Выводы}

Таким образом, в результате проведенного исследования установлено:

1 Современная экономическая ситуация в полной мере требует от государства соблюдать социальные обязательства по отношению к гражданам, выдвигая на первый план человека, его здоровье и благополучие как высшую ценность в условиях уязвимого экономического сообщества. Не являются исключением и страны ЕАЭС, вынужденные тратить экономические резервы на поддержание своих граждан в период пандемии.

2 Сравнительный анализ социальной политики проводимой странами - членами ЕАЭС в период пандемии показал наличие единого комплекса мер социальной поддержки. Это, прежде всего, выплаты по безработице и нетрудоспособности, выплаты семьям, имеющим детей, субсидирование жилищно-коммунальных платежей, и льготное кредитование. Страновая специфика характеризуется объемами сумм предоставленных пособий и критериями отбора объектов предоставления пособий.

3 Выплат, предоставленных Правительством Республики Казахстан для поддержания граждан недостаточно для покрытия реальных минимальных потребностей семьи, так как не обеспечивают покрытия реальной стоимости потребительской корзины.

4. Необходимость предоставления мер поддержки населения на протяжении продолжительного времени, обусловленное общей ситуацией с коронавирусом в мире, оказывает существенное давление на государственные бюджеты стран и может привести к возрастанию государственного долга и усугублению общеэкономических проблем. Как отмечают Т. А. Нормова, А. В. Стародубцева, А. А. Нерсесьян ключевые меры противодействия короновирусной инфекции в части необходимости обеспечения социальной поддержки граждан осложнены тем, что государство фактически вынуждено использовать собственные резервы, так как падение национальной экономики осложнилось сравнительно невысокими ценами на нефть (30 марта 2020 г. она составляла 25 долларов за баррель) [19, с.129].

Продолжительный кризис пандемии может привести к обнищанию существенной доли населения стран ЕАЭС.

\section{Список использованных источников}

1. Приказ Председателя Агентства Республики Казахстан по регулированию и развитию финансового рынка от 26 марта 2020 года, № 167 «Об утверждении Порядка приостановления выплат сумм основного долга и вознаграждения по займам населения, малого и среднего бизнеса, пострадавших в результате введения чрезвычайного положения» (с изменениями и дополнениями по состоянию на 26.05.2020 г.)

2. Поручение Президента Республики Казахстан К.К. Токаева от 23 марта 2020 года, № 20-01-7.9 «О выплатах в период чрезвычайного положения» в рамках реализации Указа Президента Республики Казахстан от 15 марта 2020 года, № 285 «О введении чрезвычайного положения в Республике Казахстан»

3. Пресс-релиз Национального банка РК от 20 июля 2020 г., № 28 «О базовой ставке»

4. Как прожиточный минимум распределяется по регионам Казахстана // https://timeskz. kz/67406-chislo-zarazhennyh-koronavirusom-vkazahstane-vyroslo-do-764.html (Дата обращения 13.01.2020)

5. В каких регионах самый большой прожиточный минимум // https://kursiv.kz/news/ obschestvo/2020-05/v-kakikh-regionakh-samyybolshoy-prozhitochnyy-minimum (Дата обращения 13.01.2020)

6. Пересмотр потребительской корзины как реальной оценки инфляции становится важным делом для Казахстана // https://dknews.kz/inner-news (Дата обращения 13.01.2020)

7. Абайдельдинов Е.М., Абдирайымова А.Е. Обеспечение прав человека на достаточное питание как важнейшая составляющая нового экономического курса Казахстана // Вестник Института законодательства и правовой информации Республики Казахстан. - 2020. - № 4 (62). C.105-110.

8. Османов Ж.Д., Моисеев П.С. Специфика обеспечения экономической безопасности в условиях усиления санкций // Социально-экономические явления и процессы. - 2015. - № 10. - URL: https:// cyberleninka.ru/article/n/spetsifika-obespecheniyaekonomicheskoy-bezopasnosti-v-usloviyah-usileniyasanktsiy (Дата обращения: 13.01.2021)

9. Мониторинг принятых государствамичленами ЕАЭС мер, направленных на преодоление негативных последствий распространения коронавирусной инфекции (COVID-2019) По состоянию на 30.12.2020//http://www.eurasiancommission. org/ru/covid-19/Documents/МОНИТОРИНГ\%20 на\% 2030\%2012.pdf (Дата обращения 13.01.2021)

10.Данные по социальным выплатам в Республике Казахстан размере 42500 // https:// informburo.kz/novosti/vyplaty-v-42-500-tengepoluchili-23-mln-kazahstancev-109930. (Дата обращения 10.02.2021)

11.Обзор антикризисных мер, применяемых государствами-членами ЕАЭС в период пандемии коронавирусной инфекции COVID-19 // https://www. 
nifi.ru/images/FILES/COVID-19/overviewEAEU.pdf (Дата обращения 10.02.2021)

12.Решение Коменданта Республики Армения Тиграна Авиняна № 54 от 23.04.2020 г. о внесении изменений и дополнений в решение Коменданта Республики Армения №27 от 31.03.2020 г.

13. Постановление Правления Национального банка от 18 мая 2020 г., № 155 «Об изменении постановления Правления Национального банка Республики Беларусь от 18 января 2013 г. № 34»

14.Панюсько А.С. Влияние пандемии COVID-19 на экономику республики Беларусь и экономику развитых стран // Архивариус. - 2020. № 4 (49). - С.55-56.

15.Головина С.Ю., Раманкулов К.С., Томашевский К.Л., Хасенов М.Х. Трудовое право и социальное обеспечение в государствах ЕАЭС в условиях пандемии Covid-19: опыт Беларуси, Казахстана, Кыргызстана и России // Российское право: образование, практика, наука. - 2020. - № 4. - C.13-17.

16. Постановление Правления Национального банка КР «О некоторых временных решениях Национального банка Кыргызской Республики по вопросу установления экономических нормативов и требований, обязательных для выполнения коммерческими банками и небанковскими финансово-кредитными организациями Кыргызской Республики» № 2020-П-12/15-7-(НПА)»

17.Указ Президента Российской Федерации от 17.12.2020, № 797 “О единовременной выплате семьям, имеющим детей”

18. Постановление Правительства РФ от 31 декабря 2020 г., № 2391 “О внесении изменений в некоторые акты Правительства Российской Федерации"

19.Нормова Т.А., Стародубцева А.В., Нерсесьян А.А. Влияние covid-19 на экономику России и меры борьбы с ним // ЕГИ. - 2020. - № 4 (30). - C.129-131.

20.Левшукова О.А., Матвеев А.С., Позоян Д.П. Возможные последствия пандемии COVID-19 на развитие экономики России // ЕГИ. - 2020. - № 3 (29). - С.191-194.

21.Федеральный закон от 23.11.2020, № 372-Ф3 “О внесении изменений в часть вторую Налогового кодекса Российской Федерации в части налогообложения доходов физических лиц, превышающих 5 миллионов рублей за налоговый период"

22. Солдатова С.С., Жидкова А.Е. Обеспечение экономической безопасности Пензенской области в современных социально-экономических условиях // StudNet. - 2020. - С.352-356.

\section{References:}

1. Order of the Chairman of the Agency of the Republic of Kazakhstan on Regulation and Development of the Financial Market No. 167 dated March 26, 2020 "On approval of the Procedure for the suspension of payments of principal and remuneration on loans to the population, small and medium-sized businesses affected by the introduction of the state of emergency" (as amended and additions as of May 26, 2020)

2. Instruction of the President of the Republic of Kazakhstan K.K. Tokayev dated March 23, 2020 No. 20-01-7.9 "On payments during a state of emergency" as part of the implementation of the Decree of the President of the Republic of Kazakhstan dated March 15, 2020 No. 285 "On the introduction of a state of emergency in the Republic of Kazakhstan"

3. Press release of the National Bank of the Republic of Kazakhstan dated July 20, 2020 No. 28 "On the base rate"

4. How the cost of living is distributed across the regions of Kazakhstan // https://imeskz.kz/67406chislo-zarazhennyh-koronavirusom-v-kazahstanevyroslo-do-764.html (Date of treatment 01/13/2020)

5. In which regions is the largest living wage // https: //kursiv.kz/news/obschestvo/2020-05/v-kakikhregionakh-samyy-bolshoy-prozhitochnyy-minimum (Date of treatment 01/13/2020)

6. Revision of the consumer basket as a real estimate of inflation is becoming an important matter for Kazakhstan // https://dknews.kz/inner-news (Date of access 13.01.2020)

7. Abaydeldinov E. M., Abdirayymova A. E. Ensuring the human right to adequate food as an essential component of the new economic course of Kazakhstan // Bulletin of the Institute of Legislation and Legal Information of the Republic of Kazakhstan. 2020. No. 4 (62). C.105-110.

8. Osmanov Zh.D., Moiseev P.S. Specificity of ensuring economic security in the context of strengthening sanctions // Socio-economic phenomena and processes. 2015. No. 10. URL: https://cyberleninka. $\mathrm{ru} / \mathrm{article} / \mathrm{n} / \mathrm{spetsifika-obespecheniya-ekonomicheskoy-}$ bezopasnosti-v-usloviyah-usileniya-sanktsiy (Date accessed: 01/13/2021)

9. Monitoring of measures taken by the EAEU member states aimed at overcoming the negative consequences of the spread of coronavirus infection (COVID-2019) As of 12/30/2020 // http: //www. eurasiancommission.org/ru/covid-19/Documents/ MONITORING \% 20 on\% 2030\% 2012.pdf (Date of access 13.01.2021)

10. Data on social payments in the Republic of Kazakhstan in the amount of 42,500// https://informburo. kz/novosti/vyplaty-v-42-500-tenge-poluchili-23-mlnkazahstancev-109930 (Date of treatment 02/10/2021) the link did not open

11. Review of anti-crisis measures applied by the EAEU member states during the COVID-19 coronavirus infection pandemic // https://www.nifi.ru/images/ FILES/COVID-19/overviewEAEU.pdf (Date of access 10.02.2021)

12. Decision of the Commandant of the Republic of Armenia Tigran Avinyan No. 54 of April 23, 2020 
on amendments and additions to the decision of the Commandant of the Republic of Armenia No. 27 of March 31, 2020.

13. Resolution of the Board of the National Bank of May 18, 2020 No. 155 "On amendments to the Resolution of the Board of the National Bank of the Republic of Belarus No. 34 of January 18, 2013"

14. Panyusko A. S. Impact of the COVID-19 pandemic on the economy of the Republic of Belarus and the economy of developed countries // Archivist. 2020. No. 4 (49). C.55-56.

15. Golovina S. Yu., Ramankulov K.S., Tomashevsky K.L., Khasenov M.Kh. Labor law and social security in the EAEU states in the context of the Covid-19 pandemic: the experience of Belarus, Kazakhstan, Kyrgyzstan and Russia // Russian law: education, practice, science. 2020. No. 4. C.13-17.

16. Resolution of the Board of the National Bank of the Kyrgyz Republic "On some temporary decisions of the National Bank of the Kyrgyz Republic on the establishment of economic standards and requirements mandatory for commercial banks and non-bank financial institutions of the Kyrgyz Republic" No. 2020-P-12 / 15-7- ( NPA) “
17. Decree of the President of the Russian Federation of December 17, 2020 No. 797 "On a onetime payment to families with children"

18. Resolution of the Government of the Russian Federation of December 31, 2020 N 2391 "On amendments to some acts of the Government of the Russian Federation"

19. Normova T. A., Starodubtseva A. V., Nersesyan A. A. Impact of covid-19 on the Russian economy and measures to combat it // EGI. 2020. No. 4 (30). C.129131.

20. Levshukova O. A., Matveev A. S., Pozoyan D. P. Possible consequences of the COVID-19 pandemic on the development of the Russian economy // EGI. 2020. No. 3 (29). C.191-194.

21. Federal Law of 23.11.2020 No. 372-FZ "On Amendments to Part Two of the Tax Code of the Russian Federation regarding the taxation of income of individuals in excess of 5 million rubles for the tax period"

22. Soldatova S.S., Zhidkova A.E. Ensuring the economic security of the Penza region in modern socioeconomic conditions // StudNet. 2020. C.352-356.

\section{Авторлар туралы мәліметтер}

Нурсымбат Сабыр - хат-хабаршы авторы, докторант, Л.Н. Гумилев атындағы Еуразия ұлттық университеті

Назерке Әбілқайыр - хат-хабаршы авторы Әл-Фараби атындағы Қазақ ұлттық университеті

\section{Information about the authors}

Nursymbat S. Sabyr - corresponding author, PhD student, L.N.Gumilev Eurasian National University NurSultan, Republic of Kazakhstan

Nazerke A.Abilkaiyr - corresponding author, Al-Farabi Kazakh National University

Дата поступления рукописи: 15.01.2021

Прошла рецензирование: 27.01.2021

Принято решение о публикации: 12.02.2021

Received: 15.01.2021

Reviewed: 27.01.2021

Accepted: 12.02.2021

Қарастыруға қабылданды: 15.01.2021

Рецензиялауды өтті: 27.01.2021

Жариялауга қабылданды: 12.02.2021 